\title{
Sistem Pendukung Keputusan Penerimaan Siswa Baru Menggunakan Metode Analytical Hierarchy Process
}

\author{
Linggar Septyoadhi $^{1}$, Mardiyanto ${ }^{2}$, Ira Luvi Indah Astutik ${ }^{3}$ \\ ${ }^{1}$ Sekolah Tinggi Teknologi Cahaya Surya Kediri \\ ${ }^{2,3}$ Sekolah Tinggi Teknologi Cahaya Surya Kediri \\ 1. linggarsep@gmail.com, ${ }^{2}$ mardiyanto@ @ cahayasurya.ac.id, ${ }^{3}$ iraluvi@gmail.com
}

\begin{abstract}
Abstrak
Penerimaan siswa baru merupakan kegiatan yang wajib dilakukan oleh setiap sekolah, baik dari tingkat SD, SMP, maupun SMA. Seperti halnya pada MAN 3 Nganjuk yang tiap tahun melakukan penerimaan siswa baru. Dari tahun ke tahun MAN 3 Nganjuk selalu mengalami peningkatan peminat yang mendaftar, sehingga diperlukan seleksi yang ketat agar siswa yang diterima benar-benar siswa yang berkompeten untuk memenuhi kuota. Sampai saat ini proses pengolahan nilai calon siswa baru yang telah mendaftar masih diolah dengan teknik manual dengan Microsoft Excel. Untuk mempermudah dan membantu MAN 3 Nganjuk dalam proses penyeleksian siswa baru maka dibutuhkan sebuah Sistem Pendukung Keputusan (SPK) dengan metode Analytical Hierarchy Process (AHP). Metode Analytical Hierarchy Process (AHP) dipilih karena dapat menghitung bobot-bobot dari kriteria tiap siswa, hasil dari perhitungan metode AHP selanjutnya akan digunakan sebagai acuan untuk penentuan siswa baru yang diterima yang diurutkan dari rangking tertinggi ke terendah.
\end{abstract}

Kata Kunci-AHP, penerimaan siswa baru, sistem pendukung keputusan

\section{PENDAHULUAN}

Pada template ini memiliki beberapa aturan penulisan, bagian ini menjelaskan latar Tahun ajaran baru merupakan awal dimulai proses pembelajaran yang akan dilaksanakan di sekolah baik di SMA, SMP, dan Sekolah dasar. Selain itu penerimaan siswa baru juga akan dilaksanakan di sekolah-sekolah setiap tahunnya. Penerimaan siswa baru ini dilakukan dengan cara menyeleksi, melakukan pemilihan siswa yang tepat yang didasarkan atas kriteria-kriteria yang sudah ditentukan oleh masing-masing sekolah yang nanti digunakan untuk standar dalam penerimaan siswa baru tersebut.

MAN 3 Nganjuk merupakan salah satu lembaga pendidikan yang terletak di Desa Baleturi Kecamatan Prambon Kabupaten Nganjuk dan juga mengadakan seleksi penerimaan siswa baru tiap tahunnya. MAN 3 Nganjuk memiliki jumlah pendaftar yang cukup meningkat tiap tahun, masalah pengambilan keputusan untuk penerimaan siswa baru di MAN 3 Nganjuk masih mengalami kendala, yaitu masih subyektif dalam perhitungan nilai-nilai yang dilakukan oleh pihak sekolah dalam menentukan siswa yang akan diterima di MAN 3 Nganjuk, yang tentu membuat pihak sekolah membutuhkan waktu yang relatif lebih lama dalam mengambil keputusan. Menghadapi masalah tersebut, peneliti ingin membuat sebuah program yang dapat mengolah prosesproses penyeleksian siswa baru tersebut secara terkomputerisasi, dengan menjadikan objek penelitian dalam membangun Sistem Pendukung Keputusan Seleksi Penerimaan Siswa Baru menggunakan metode Analytical Hierarchy Process (AHP). 
Analytical Hierarchy Process (AHP) merupakan metode pendukung pengambilan keputusan yang akan menghitung bobot-bobot dari kriteria tiap siswa, hasil perhitungan ini akan digunakan sebagai acuan atau perbandingan untuk menentukan diterima atau tidak siswa [1]. Salah satu penggunaan metode Analytical Hierarchy Process (AHP) adalah yang dilakukan oleh [2] mengembangkan 2 metode sebagai pemecahan permasalahan. Kriteria-kriteria yang digunakan antara lain Kemampuan, keterampilan dan kecerdasan. Metode yang digunakan adalah Analytical Hierarchy Process (AHP) dan Simple Additive Weighting (SAW) untuk menentukan perangkingan siswa serta hasil kelulusan siswa yang diterima. Serta penelitian yang dilakukan oleh [3] menggunakan kriteria utama yang digunakan antara lain nilai siswa, tes kesehatan, tes akademik dan psikotes, data tersebut dikumpulkan dan menggunakan metode Analytical Hierarchy Process (AHP) untuk menentukan keputusan dan juga perangkingan siswa yang diterima.

Kedua penelitian diatas penggunaan metode Analytical Hierarchy Process (AHP) bisa membantu dalam menyelesaikan permasalahan terkait seleksi penerimaan siswa baru di setiap sekolah, dari hasil pengujian sistem diatas sudah sesuai dan berjalan dengan baik, ini dapat dilihat dari hasil uji respon dan status berhasil pada masingmasing pengujian baik itu uji fungsionalitas, uji kesesuaian proses, uji kesesuaian input dengan output, uji kelayakan sistem, serta uji kesesuaian algoritma.

\section{METODE PENELITIAN}

\subsection{Metode Pengumpulan Data}

Teknik untuk pengumpulan data dalam penelitian ini terbagi menjadi tiga tahap yaitu wawancara, pengamatan dan studi literatur [4]. Wawancara (Interview) dengan teknik pengumpulan data yang dilakukan dengan cara tanya jawab atau dialog secara langsung dengan pihak-pihak yang terkait dengan penelitian yang dilakukan. Dalam hal ini penulis melakukan tanya jawab kepada pihak MAN 3 Nganjuk, khususnya panitia penerimaan siswa baru.

Pengamatan (Observasi) dengan teknik pengumpulan data mengadakan tinjauan secara langsung ke objek yang diteliti serta mengumpulkan data-data informasi yang dibutuhkan. Untuk mendapatkan data dan informasi yang bersifat nyata, maka penulis melakukan pengamatan langsung di MAN 3 Nganjuk tentang tata cara proses penerimaan siswa baru.

Studi Literatur untuk mendapatkan data-data yang bersifat teoritis maka penulis melakukan pengumpulan data dengan cara membaca dan mempelajari buku-buku, jurnal, makalah, internet ataupun referensi lain yang berhubungan dengan masalah pembahasan.

\subsection{Analisis Data}

a. Kriteria Penyeleksian

Hasil dari identifikasi data dengan pihak sekolah tersebut adalah kriteria yang didapatkan dalam proses pengumpulan data yakni kriteria utama adalah nilai Tes IQ, Nilai Danem dan Piagam Penghargaan. Tiga (3) kriteria utama tersebut masing-masing 2 kriteria utama memiliki sub-sub kriteria yang sama yaitu mulai dari rentang rendah, cukup, baik dan sangat baik, sementara untuk piagam ada sub kriteria piagam untuk kab/kota, provinsi dan nasional seperti tabel di bawah ini: 
b. Langkah perhitungan Metode AHP

Pada dasarnya langkah-langkah penyelesaikan dalam metode AHP [4] adalah sebagai berikut :

- Menentukan jenis-jenis kriteria permasalahan yang dihadapi

- Menyusun kriteria-kriteria tersebut dalam bentuk matriks perbandingan berpasangan.

- Menjumlahkan matriks kolom.

- Menghitung nilai elemen kolom kriteria dengan rumus masing-masing elemen kolom dibagi dengan jumlah matriks kolom.

- Menghitung nilai prioritas kriteria dengan rumus menjumlahkan matriks baris hasil langkah 4 dan hasilnya 5 dibagi dengan jumlah kriteria.

- Menguji konsistensi setiap matriks berpasangan dengan menghitung Lambda max dengan rumus :

$\lambda \max =\frac{\Sigma \lambda}{\mathrm{n}}$

- Menghitung Indeks Konsistensi (CI) dengan rumus :

$\mathrm{CI}=\frac{\lambda \max -\mathrm{n}}{\mathrm{n}-1}$

- Menghitung Rasio Konsistensi (CR) dengan rumus :

$C \mathrm{R}=\frac{\mathrm{CI}}{\mathrm{RI}}$.

- Hasil akhirnya berupa prioritas global sebagai nilai yang digunakan oleh pengambil keputusan berdasarkan skor yang tertinggi.

c. Perancangan Sistem

Komponen yang digunakan dalam perancangan sistem adalah menggunakan Context Diagram dan Data Flow Diagram. Diagram Konteks adalah diagram yang menggambarkan sumber serta tujuan data yang akan diproses atau dengan kata lain diagram tersebut digunakan untuk menggambarkan sistem secara umum/global dari keseluruhan sistem yang ada atau bisa di ambil kesimpulan bahwa diagram konteks merupakan diagram yang menggambarkan jalannya proses secara keseluruhan atau umum [6]. Data Flow Diagram atau DFD merupakan diagram yang menggunakan notasi-notasi atau simbol-simbol untuk menggambarkan sistem jaringan kerja antar fungsi-fungsi yang berhubungan satu sama lain dengan aliran dan penyimpanan data.

Tabel 1. Simbol-simbol Data Flow Diagram

\begin{tabular}{|l|l|}
\hline Simbol & Keterangan \\
\hline & $\begin{array}{l}\text { Entitas disimbolkan dalam bentuk persegi } \\
\text { panjang yang mewakili entity luar dimana } \\
\text { sistem berkomunikasi. }\end{array}$ \\
\hline & $\begin{array}{l}\text { Proses disimbolkan dalam bentuk } \\
\text { lingkaran. Inputan yang dimasukkan } \\
\text { kedalam sistem akan diubah menjadi } \\
\text { outputan melalui proses ini. }\end{array}$ \\
\hline & $\begin{array}{l}\text { Tabel disimbolkan dengan garis sejajar, } \\
\text { yang digunakan untuk memodelkan } \\
\text { kumpulan data. }\end{array}$ \\
\hline
\end{tabular}




\begin{tabular}{|l|l|}
\hline Simbol & Keterangan \\
\hline$\longleftrightarrow$ & $\begin{array}{l}\text { Arus/aliran data disimbolkan dengan } \\
\text { tanda anak panah. Dapat menunjukkan } \\
\text { arus data yang dapat berupa masukan atau } \\
\text { hasil proses sistem. }\end{array}$ \\
\hline
\end{tabular}

Penyusunan kebutuhan dalam perancangan sistem pendukung keputusan penerimaan siswa baru menggunakan metode Analytical Hierarchy Process (AHP) terdiri dari kebutuhan perangkat keras dan kebutuhan perangkat lunak.

Kebutuhan Perangkat Keras dalam membangun aplikasi ini menggunakan sebuah laptop dengan spesifikasi Laptop nToshiba C800D, Processor AMD E1-1200 APU 1,4 GHZ, RAM 2GB dan Harddisk 500GB

Adapun perangkat lunak yang digunakan dalam membangun aplikasi ini adalah dengan menggunakan Sistem operasi Microsoft Windows 7, Web Browser Google Chrome V38.0.1, Xampp V3.2.1 untuk merancang database system yang dibuat, dan Sublime Text 3 yang digunakan sebagai software untuk merancang aplikasi.

\section{HASIL DAN PEMBAHASAN}

\subsection{Hasil Pengumpulan Data}

Hasil pengumpulan data setelah melakukan proses identifikasi data di MAN 3 Nganjuk didapatkan beberapa kriteria yang akan digunakan dalam penyeleksian siswa baru menggunakan metode Analytical Hierarchy Process (AHP) yaitu Tes IQ, Nilai Danem dan Piagam Penghargaan dan diperoleh data siswa sebanyak 200 siswa yang akan digunakan sebagai data sampel dalam penelitian ini.

\subsection{Hasil perhitungan Metode AHP}

Hasil perhitungan AHP dimulai dengan melakukan perbandingan berpasangan dengan pendekatan ini digunakan pendekatan subjektif yaitu nilai bobot ditentukan berdasarkan subjektifitas dari para pengambil keputusan berikut seperti pada tabel 2 .

Tabel 2 Perbandingan Berpasangan

\begin{tabular}{|l|l|c|c|}
\hline Kriteria & Tes IQ & Danem & Piagam \\
\hline Tes IQ & 1 & 3 & 5 \\
\hline Danem & 0,333 & 1 & 3 \\
\hline Piagam & 0,2 & 0,333 & 1 \\
\hline Jumlah & 1,533 & 4,333 & 9 \\
\hline
\end{tabular}

Kemudian dilakukan normalisasi dari hasil perbandingan berpasangan seperti tabel 3 berikut ini

Tabel 3. Normalisasi

\begin{tabular}{|l|l|l|l|l|}
\hline Kriteria & Tes IQ & Danem & Piagam & Jumlah \\
\hline Tes IQ & 0,652 & 0,692 & 0,556 & 1,900 \\
\hline Danem & 0,217 & 0,231 & 0,333 & 0,781 \\
\hline Piagam & 0,130 & 0,077 & 0,111 & 0,318 \\
\hline
\end{tabular}


Setelah dilakukan normalisai akan ditentukan berapa prioritas dari masing-masing kriteria dengna membagi jumlah hasil normalisasi dengan banyaknya kriteria seperti pada tabel 4 berikut ini :

Tabel 4. Prioritas kriteria

\begin{tabular}{|l|l|}
\hline Kriteria & Prioritas \\
\hline Tes IQ & 0,633 \\
\hline Danem & 0,260 \\
\hline Piagam & 0,106 \\
\hline
\end{tabular}

Langkah terakhir adalah dilakukan perhitungan konsistensi, apakah sudah konsiten kah perhitungan yang telah dilangsungkan jika belum konsisten perhitungan belum dapat digunakan sebagai acauan dalam penyeleksian, berikut perhitungan $\lambda$ max, CI, dan CR.

$\lambda \max$ diperoleh dari hasil perkalian matriks awal dengan eigen vector kemudian hasilnya dibagi jumlah kriteria.

$$
\begin{aligned}
\lambda \max & =\left(\begin{array}{ccc}
1 & 3 & 5 \\
0,333 & 1 & 3 \\
0,2 & 0,333 & 1
\end{array}\right) \times\left(\begin{array}{l}
0,633 \\
0,260 \\
0,106
\end{array}\right) \\
& =\left(\begin{array}{l}
1,945 \\
0,790 \\
0,319
\end{array}\right)
\end{aligned}
$$

$\lambda \max =(1,945 / 0,633)+0,790 / 0,260+0,319 / 0,106) / 3=3,038$

Menghitung indeks konsistensi (CI)

$\mathrm{CI}=\lambda \max -\mathrm{n} / \mathrm{n}-1=3,038-3 / 3-1=0,038 / 2=0,019$

Menghitung rasio konsistensi (RI) dengan nilai RI untuk $\mathrm{n}=3$ adalah 0,58

$\mathrm{CR}=\mathrm{CI} / \mathrm{RI}=0,019 / 0,58=0,033$

Karena CR $<0,1$ berarti preferensi pembobotan adalah konsisten.

\subsection{Context Diagram}

Diagram konteks berfungsi untuk menggambarkan keterkaitan data antara sistem dengan bagian-bagian luar. Context diagram tersebut sebagai berikut :

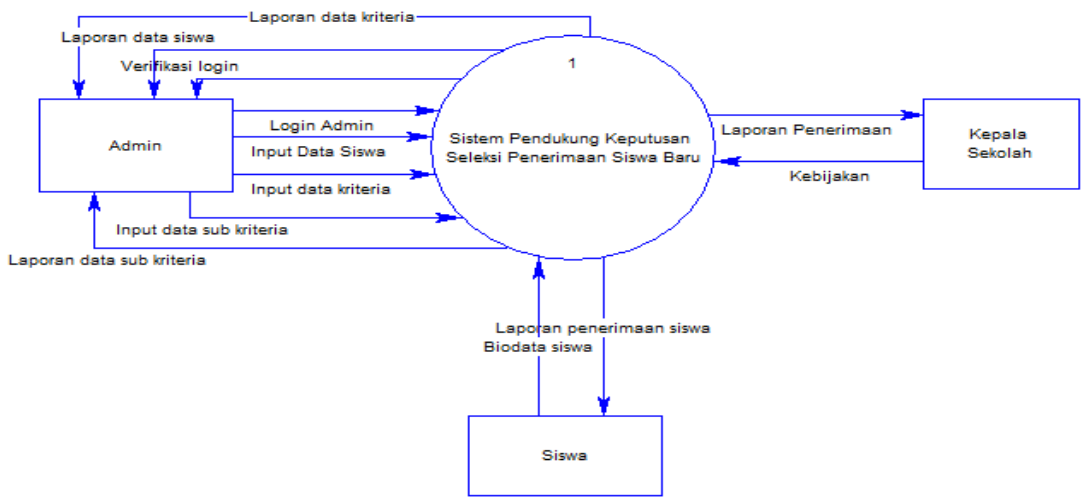

Gambar 1. Context Diagram 


\subsection{Data Flow Diagram level 0}

DFD Merupakan pengembangan dari diagram konteks, yang menggambarkan suatu sistem data mengalir dimana data tersebut akan disimpan. Berikut ini adalah DFD (Data Flow Diagram) Level 0 :

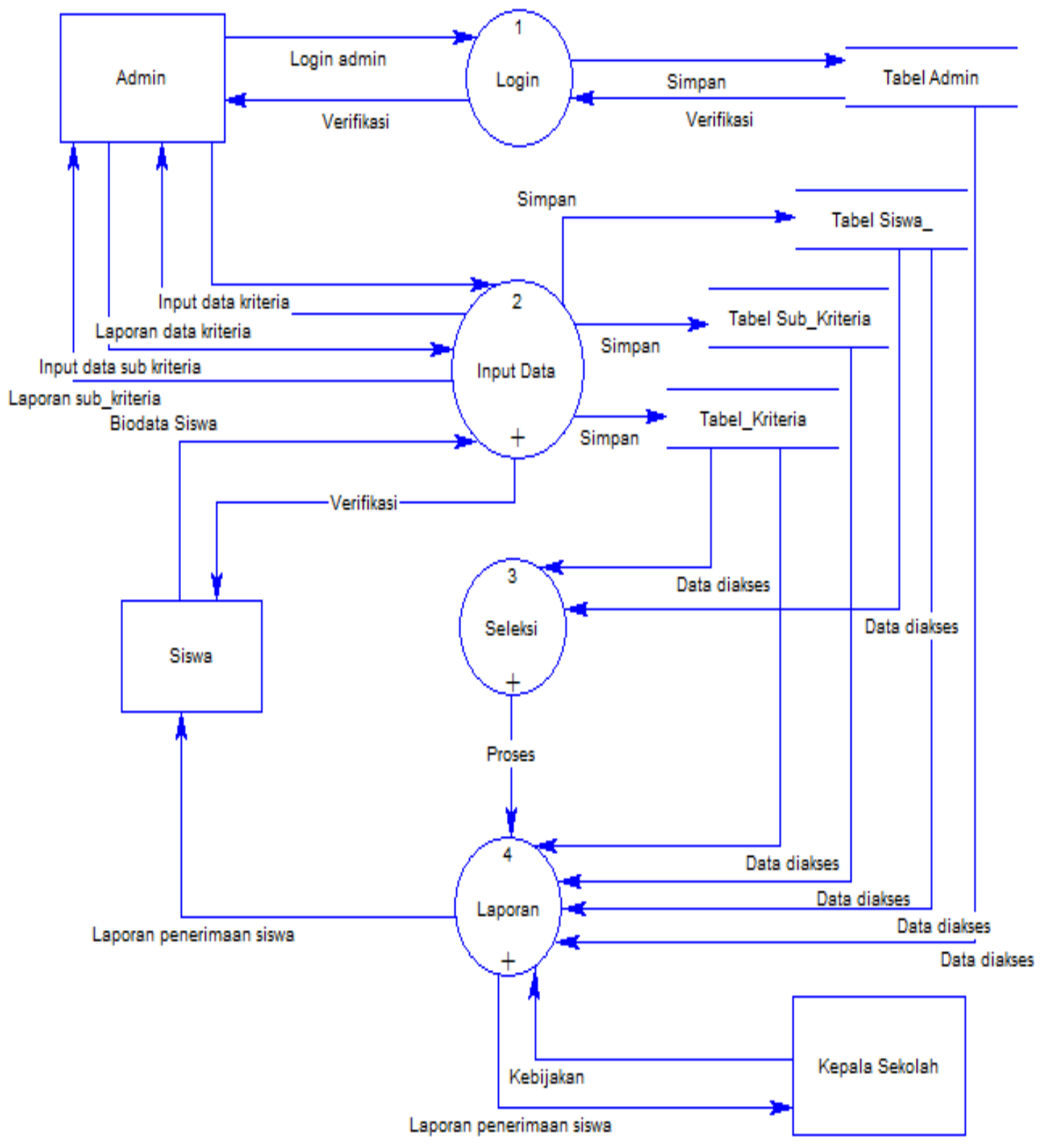

Gambar 2. DFD Level 0 


\subsection{User Interface}

a. Halaman Siswa

Halaman siswa adalah halaman yang digunakan untuk melihat data-data siswa baru, halaman ini juga berfungsi untuk menambah, mengubah dan menghapus data siswa baru seperti pada gambar 3 berikut :

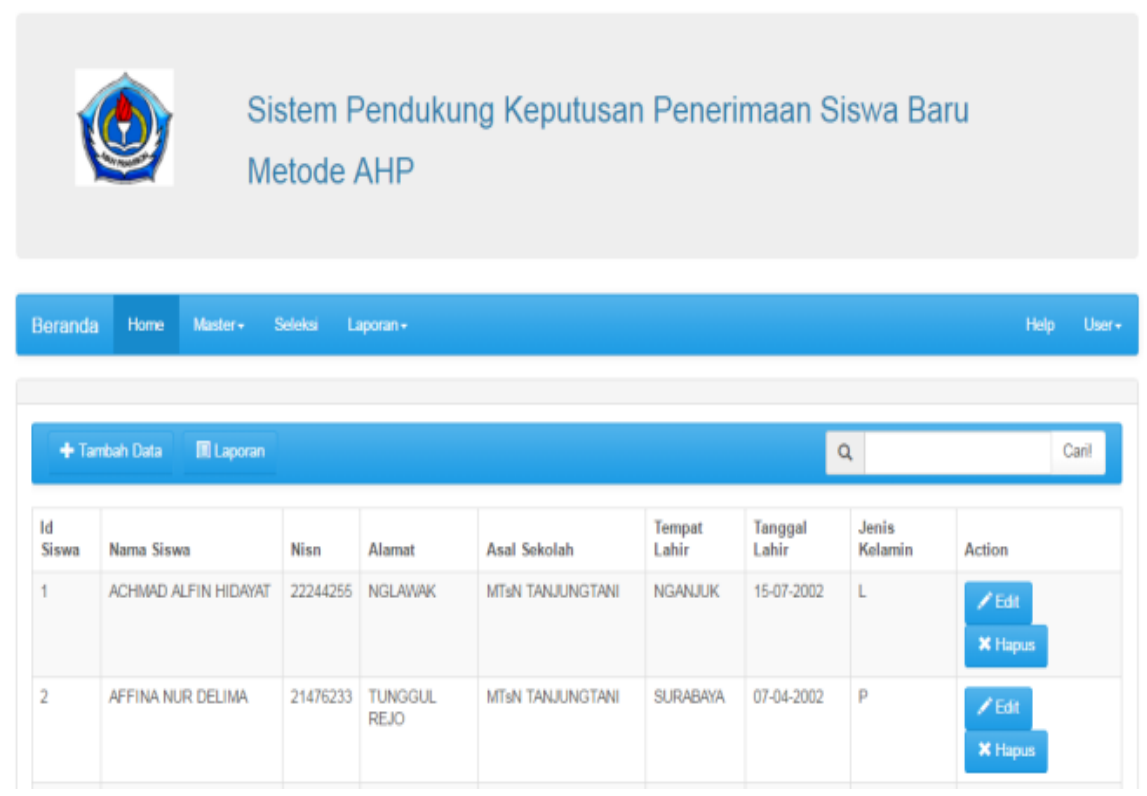

\section{Gambar 3. Halaman Siswa}

\section{b. Halaman Perbandingan Berpasangan}

Halaman ini berisi tentang proses awal dari pembobotan kriteria dengan memasukkan masing-masing bobot criteria untuk dihitung dan membentuk matriks perbandingan berpasangan seperti pada gambar 4 berikut:

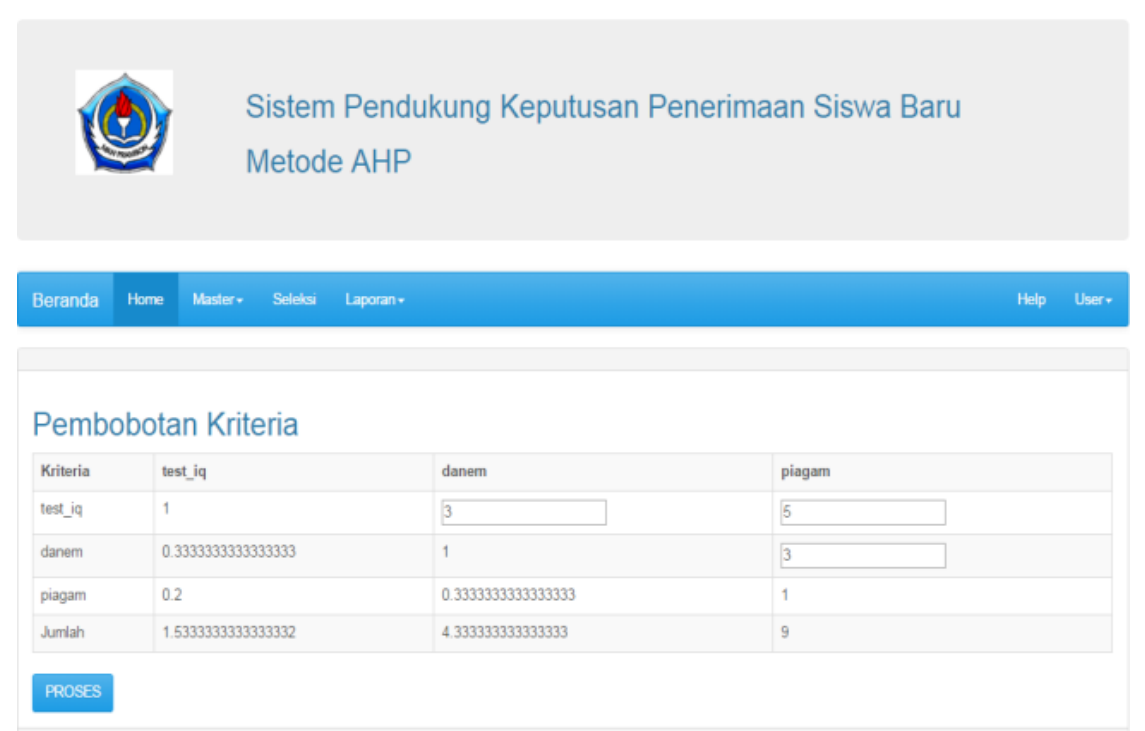

Gambar 4. Perbandingan Berpasangan 


\section{c. Halaman Normalisasi}

Halaman normalisasi kriteria berisi hasil pembagian matriks perbandingan berpasangan dengan jumlah total dan akan mendapatkan eigen vector seperti pada gambar 5 berikut :

\begin{tabular}{|c|c|c|c|c|c|}
\hline Kriteria & test iq & danem & piagam & Jumlah & Eigen Vector \\
\hline test iq & 0.65217391304348 & 0.69230769230769 & 0.55555555555556 & 1.9000371609067 & 0.63334572030224 \\
\hline danem & 0.21739130434783 & 0.23076923076923 & 0.33333333333333 & 0.78149386845039 & 0.26049795615013 \\
\hline piagam & 0.1304347826087 & 0.076923076923077 & 0.111111111111111 & 0.31846897064288 & 0.10615632354763 \\
\hline Total & 1 & 1 & 1 & & \\
\hline
\end{tabular}

Gambar 5. Normalisasi

\section{d. Halaman Penerimaan Siswa}

Halaman penerimaan siswa baru merupakan halaman laporan yang digunakan untuk print out data-data dari siswa baru yang diterima. Berikut tampilan halaman seperti pada gambar 6 berikut:

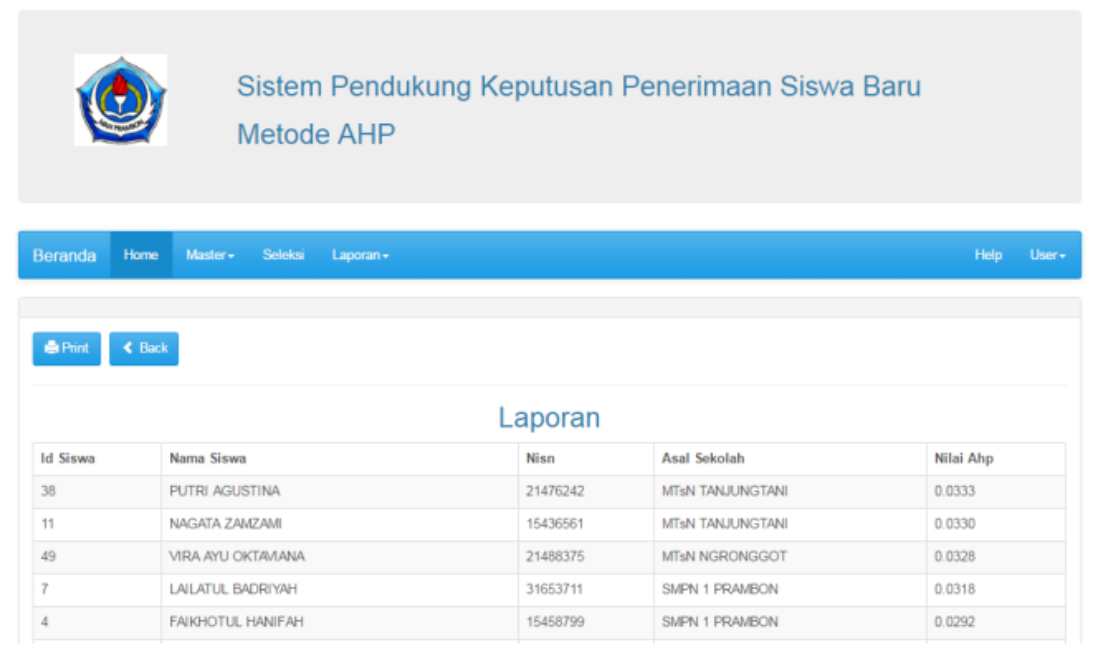

Gambar 6. Halaman Penerimaan Siswa

\section{KESIMPULAN}

Berdasarkan hasil Sistem Pendukung Keputusan Penerimaan Siswa Baru di MAN 3 Nganjuk yang telah dibuat, maka dapat diambil kesimpulan metode Analytical Hierarchy Process (AHP) berhasil diterapkan dalam penyeleksian siswa baru, dengan menggunakan kriteria Tes IQ, Nilai Danem dan Piagam Kejuaraan yangb telah mampu digunakan sebagai acuan dalam seleksi penerimaan siswa baru MAN 3 Nganjuk. Sistem yang telah dibuat membantu MAN 3 Nganjuk dalam penentuan penerimaan siswa baru dengan hasil rangking terurut dari nilai tertinggi hingga terendah. Saran untuk pengembangan lebih lanjut terhadap penelitian ini adalah dengan Melakukan 
perhitungan menggunakan metode yang lain atau perbandingan dengan metode lain, sehingga dapat diketahui keakuratan hasil pada permasalahan yang sama namun dengan metode yang berbeda. Dapat dikembangkan dengan menambahkan data lain yang mendukung seleksi penerimaan siswa baru, misalnya penambahan kriteria serta desain sistem lebih user friendly agar ketika digunakan menjadi lebih mudah.

\section{DAFTAR PUSTAKA}

[1] Marimin, 2004. Teknik dan Aplikasi Pengambilan Keputusan Kriteria Majemuk, Jakarta, PT Grasindo.

[2] Putra, Putu A.S, 2016. Pengembangan Sistem Pendukung Keputusan Penerimaan Siswa Baru di SMA Negeri 1 Seririt dengan Metode AHP dan Metode SAW. Volume 5 Nomor 1, KARMAPATI, Singaraja.

[3] Damopolii, Mayang Pratiwi, 2014. Sistem Pendukung Keputusan Penerimaan Siswa Baru di SMA Negeri 3 Gorontalo Menggunakan Metode AHP, [Online], http://www.smantig.com/.

[4] Turban, Efraim, , "Decision Support Systems and Intelligent Systems" Yogyakarta: Andi Offset.

[5] Kusrini, 2007. Konsep dan Aplikasi Sistem Pendukung Keputusan, Yogyakarta: Andi Offset.

[6] Jogiyanto, 2010, Analisis dan Desain Sistem Informasi, Edisi IV, Yogyakarta: Andi Offset. 